\title{
Design and Simulation of Slot Dimensions in Aperture Coupled Hemispherical Dielectric Resonator Antenna
}

\author{
M Syamala, B Kanthamma, U Jaya Lakshmi
}

\begin{abstract}
Aperture coupled novel shaped Hemispherical Dielectric Resonator Antenna (HDRA) and the various dimensions of slots are designed and analyzed by hfss software. The dielectric constant of dielectric hemisphere is $\epsilon=9.8$ and the substrate of dielectric constant is 2.96. aperture coupled novel shaped Hemispherical Dielectric Resonator Antenna (HDRA) parameters are presented in this paper.. The effects of changing the slot length, slot width and position of slot on the antenna parameters and are presented in this paper, which are used for directive gain applications. As the change of slot dimension, it is observed that at the resonant frequency, it gives high gain and high negative return loss.
\end{abstract}

Key words: HDRA, Aperture Coupled, Antenna parameters

\section{INTRODUCTION}

In the digital Era, the size of antenna plays important role in the applications. The novel Hemispherical Dielectric Resonator Antenna (HDRA) has the advantage of no ohmic losses at higher frequencies. The antennas are in different shapes, cylindrical, hemispherical, etc. The size and the antenna parameters of these shapes has its own advantages.

The analysis of hemispherical geometry do not need any magnetic wall assumption and can be modeled with the interface between the air and dielectric[1]. The methods of feeding mechanisms are aperture coupled, slot coupled, waveguide feed, microstrip feed, and coaxial probes feed are used.

The different methods are by cutting slots and sections or the surface area is increasing in modifying the shapes of the DRA to improve the HDRA antenna parameters. The patch location and dimensions gives the circularly polarized HDRA frequency and axial ratio[2]. The parasitic patch HDRA aperture coupled has been used to improve the bandwidth of HDRA polarized linearly[3]. The patch location and dimensions determine the circularly polarized HDRA frequency and axial ratio[4].

The analysis of novel aperture coupled described in two steps. The first step is place HDRA on the ground plane and the other is place microstrip line under the ground plane. The first one analyzed by the matching mode method to determine the slot's Green's function [5].

The second microstrip line is analyzed by the reciprocity method. The slot dimensions modifies operating

Revised Manuscript Received on December 13, 2019.

* Correspondence Author

M.Syamala*,Assistant professorECE,.ANITS Visakhapatnam Email: msyamala869@gmail.com

B Kanthamma ,Research Scholar, Dept. of ECE, AUCE, AU, Visakhapatnam, Andhra Pradesh, INDIA

Email: kanthamma.bokka@gmail.com

Dr U Jaya Lakshmi, ECE, Technical Education, Bheemunipatnam, Visakhapatnam, Andhra Pradesh, INDIA. Email: drjayauddanti@gmail.com frequency and bandwidth. If HDRA placed on a cylindrical ground plane gives high gain and omnidirectional radiation pattern[6].

\section{NOVEL HDRA WITH SLOT}

The microstripline energy couples to the hemispherical DR through the slot width $W$, length $L$. The slot length $L$ and radius a and its displacement from $\mathrm{y}$-axis is $\mathrm{x}$ and the $\mathrm{z}$-axis is $\mathrm{y}$.

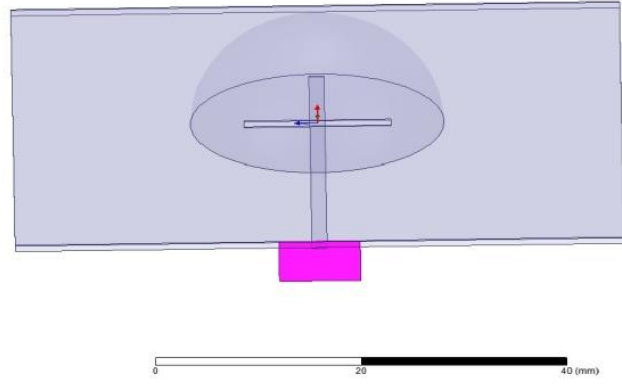

Fig. 1.The aperture coupled novel hemispherical dielectric resonator antenna

The sphere of radius $12.5 \mathrm{~mm}\left(1^{00}\right)$, cut by half of the radius in the geometry of the proposed antenna structure from the top. The hemisphere height $h=\mathrm{a}=$ radius The $11 \mathrm{~cm} x 11 \mathrm{~cm}$ is size of ground plane. The substrate height of substrate = $0.635 \mathrm{~mm}$ and dielectric constant $=2.96$

The novel Hemispherical DRA geometry design equation is given by,

$$
f=\quad \begin{gathered}
4: 775 £ \\
10^{7} \operatorname{Re}\left(K_{a}\right) \\
\\
(€) a
\end{gathered}
$$

Where the hemisphere radius $=a, \epsilon=$ the dielectric constant, $f$ = resonant frequency , and $K_{a}=$ the wave number.

\section{RESULTS AND DISCUSSION}

CASE- I : Aperture coupled novel hemispherical dielectric resonator antenna is excited with a slot and its position $x=0$ $\mathrm{mm}, y=0 \mathrm{~mm}$ from the central hole. The slot length is $14 \mathrm{~mm}$ and slot width is $1.5 \mathrm{~mm}$. The feed position excited in all modes and provide the impedance matching. The HRDA parameters such as return loss, gain and VSWR verses frequency plots are presented in figures 2-4. 


\section{Design and Simulation of Slot Dimensions in Aperture Coupled Hemispherical Dielectric Resonator Antenna}

CASE- II : Aperture coupled novel hemispherical dielectric resonator antenna is excited with a slot and its position $x=0$ $\mathrm{mm}, y=0 m m$ from the central hole. The slot length is $14 \mathrm{~mm}$ and slot width is $1.3 \mathrm{~mm}$. The HRDA parameters such as return loss, gain and VSWR verses frequency plots are presented in figures 5-7.

CASE- III : Aperture coupled hemispherical dielectric antenna is excited with a slot position at $x=-1.5 \mathrm{~mm}$ and $y=$ $-1.5 \mathrm{~mm}$ from the central hole. The slot length is $14.5 \mathrm{~mm}$ and slot width is $1.5 \mathrm{~mm}$. The HRDA parameters such as return loss, gain and VSWR verses frequency plots are presented in figures 8-10.

CASE- IV : Aperture coupled hemispherical dielectric antenna is excited with a slot position at $x=-1.5 \mathrm{~mm}$ and $y=$ $-1.5 \mathrm{~mm}$ from the central hole. The slot length is $14.5 \mathrm{~mm}$ and slot width is $1.3 \mathrm{~mm}$. The HRDA parameters such as return loss, gain and VSWR verses frequency plots are presented in figures 11-13.

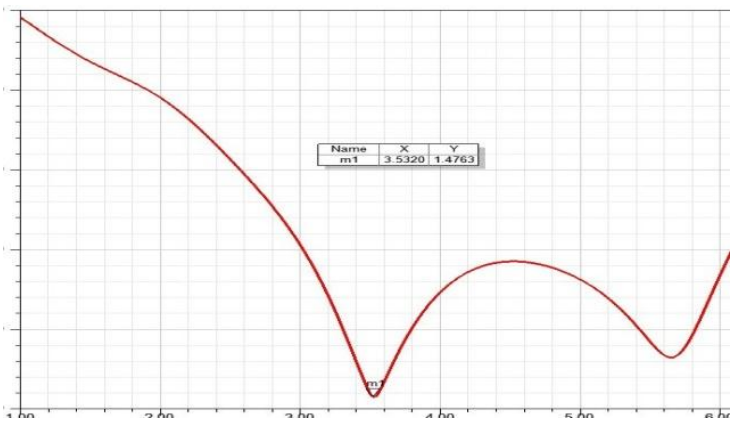

Fig. 2 Frequency Vs VSWR plot for case -I

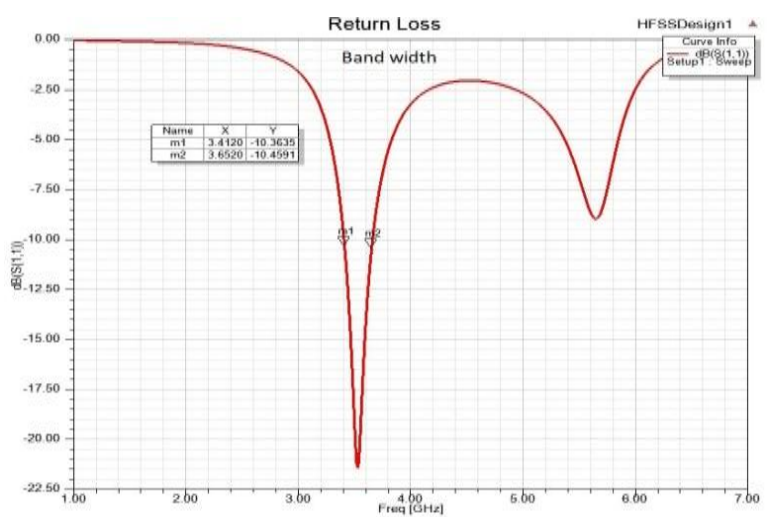

Fig. 3..Frequency Vs Return loss plot for case -I

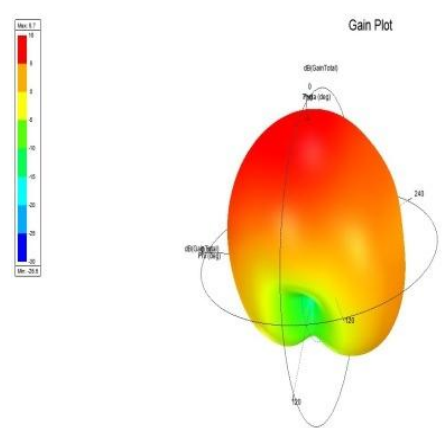

Fig. 4. Frequency Vs Gain 3- D plot for case -I



Fig.5. Frequency Vs VSWR plot for case -II

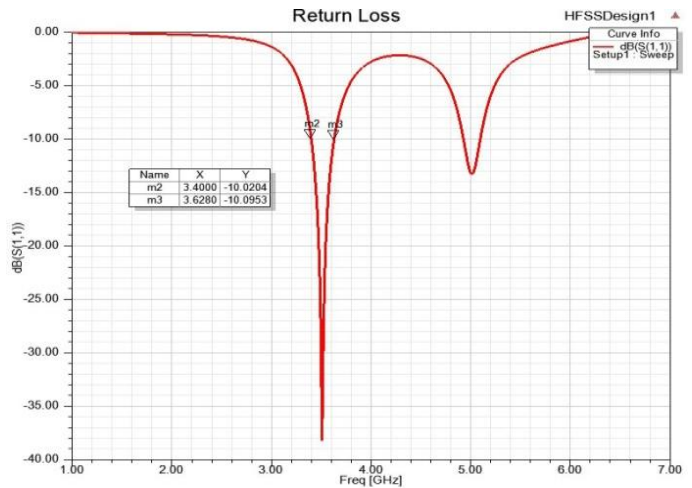

Fig.6.Frequency Vs Return loss plot for case -II

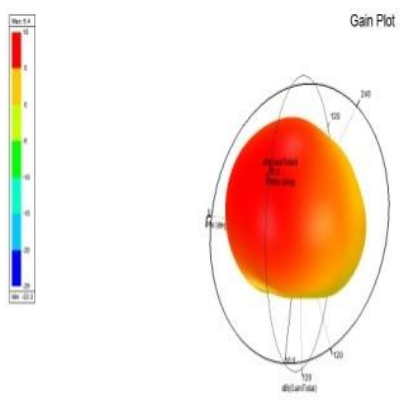

Fig.7 Frequency Vs Gain 3- D plot for case -II

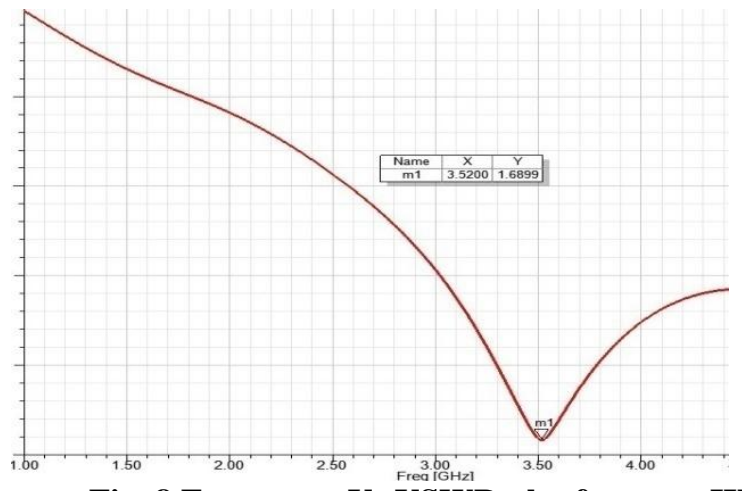

Fig. 8.Frequency Vs VSWR plot for case -III 




Fig.9. Frequency Vs Return loss plot for case -III

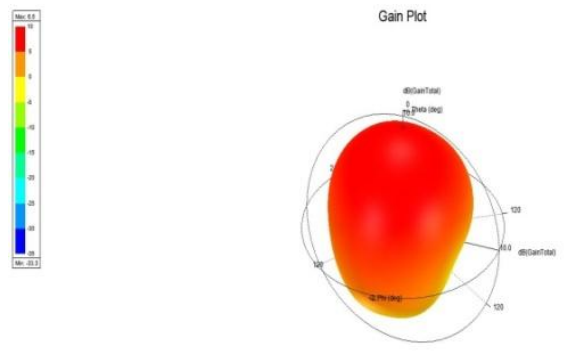

Fig.10. Frequency Vs Gain 3- D plot for case -III



Fig. 11.Frequency Vs VSWR plot for case -IV

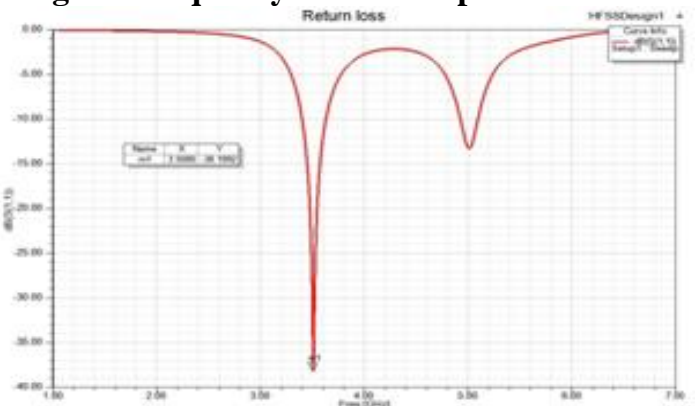

Fig. 12. Frequency Vs Return loss plot for case -IV


Fig. 13 Frequency Vs Gain 3- D Gain plot for case -IV
Table I:Comparison results for four cases

\begin{tabular}{|l|r|r|r|r|r|r|r|}
\hline CASE & $\begin{array}{l}\text { Slot } \\
\text { length } \\
(\mathrm{mm})\end{array}$ & $\begin{array}{l}\text { Slot } \\
\text { width } \\
(\mathrm{mm})\end{array}$ & $\begin{array}{l}\text { Slot } \\
\text { position } \\
\left(\mathrm{x}_{k} \mathrm{y}\right)\end{array}$ & $\begin{array}{l}\text { Return } \\
\text { loss(dB) }\end{array}$ & VSWR & Frequency & GAIN \\
$(\mathrm{GHz})$ & & \\
\hline I & 14 & 1.5 & 0 & -21.4 & 1.47 & 3.53 & 5.7 \\
\hline II & 14 & 1.3 & 0 & -22.1 & 1.36 & 3.53 & 5.4 \\
\hline III & 14.5 & 1.5 & -1.5 & -20.2 & 1.6 & 3.52 & 6.5 \\
\hline IV & 14.5 & 1.3 & -3 & -38 & 0.21 & 3.5 & 6.6 \\
\hline
\end{tabular}

\section{CONCLUSION}

The Investigations are carried on aperture coupled novel Hemispherical Dielectric Resonator Antenna with slots . The variations in length, width and position of the slot and the effects in the antenna parameters are also studied. It is revealed that the Gain and return loss are improved. The antenna gives more negative return loss and high gain for increasing slot width and slot position. It is useful for high directivity applications.

\section{ACKNOWLEDGMENT}

We are thankful to department of E \&EC ,IIT, Kharagapur. They Encoraged to work on the HR antennas.

\section{REFERENCES}

1. 1 " Theory and experiment of an aperture coupled hemispherical dielectric resonator antenna", by K.W. Leung, and co... L, , Vol.AP-43, Issue 11, IEEE trans Antenna Propagation. pp 1192-1198,Nov1995

2. "Resonant hemispherical dielectric antenna," by McAllister and co. Vol. 20, No. 16, Electronics Letters, page no.s 657-659, 1984.

3. "New half hemispherical dielectric resonator antenna for broadband monopole type radiation," by Guha, D. and Y. M. M. Antar, IEEE Transactions on Antennas and Propagation, Vol. 54, No. 12, 36213628, Dec. 2006

4. 4. "Analysis of a broadband hemispherical dielectric resonator antenna with a dielectric coating," by K.L Wong. and Chen N. C. journal Microwave and Optical Technology, Vol. 7, No. 2,

5. 5. "The slot coupled hemispherical dielectric resonator antenna with a parasitic patch: Applications to the circularly polarized antenna and wide band antenna," by K. W Leung, . and H. K. Ng,Vol. 53, No. 5, , IEEE Transactions on Antennas and Propagation, pg no.s 1762-1769, May 2005.

6. 6. "Hemispherical DRA antennas mounted on or embedded in circular cylindrical surface for producing omnidirectional radiation pattern," by S. H Zainud-Deen,., N. A. El-Shalaby, and Awadalla, K.H , Vol. 4, International Journal of Communications, Network and System Sciences, pgno.s 601-608, Sep. 2011. 
Design and Simulation of Slot Dimensions in Aperture Coupled Hemispherical Dielectric Resonator Antenna

\section{AUTHORS PROFILE}

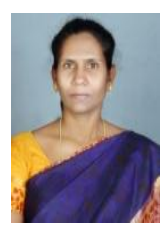

I M Syamal completed my B.E and M..Tech in Andhra University and persuing $\mathrm{PhD}$ in Andhra University.My interesting subjects are electronic devices and circuits , EMFT,antennas \& microwaves.I have published my papers in national and international conferences.



I,B. Kanthamma completed my B.E andM.E in Andhra University and persuingPhD in Andhra University.My interesting subjects are circuit theory and antennas. I have published my papers in four international journals, two international conferences

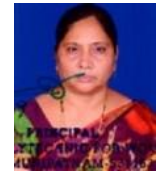

I,Dr U Jaya Lakshmi completed my B.E in JNT university andM.E, Ph.D in Andhra University .My interesting subjects are EMF and antennas. I have published my papers in international journals, national journals, international conferences and national conferences. 